\title{
COMPETITIVE INDUSTRIAL PERFORMANCE INDEX AND ITS DRIVERS: A COMPARATIVE ANALYSIS ON TURKEY AND SELECTED COUNTRIES
}

\author{
Research Ass. Çăgaçan DEĞER, Middle East Technical University, Faculty of \\ Economics and Administrative Sciences, Department of Economics, \\ cagacan@metu.edu.tr \\ Research Ass. Burcu TÜRKCAN, Ege University, Faculty of Economics and \\ Administrative Sciences, Department of Economics, burcu.turkcan@ege.edu.tr \\ Prof. Dr. Neşe KUMRAL, Ege University, Faculty of Economics and \\ Administrative Sciences, Department of Economics, nese.kumral@ege.edu.tr
}

\begin{abstract}
Competitiveness of manufacturing industry is regarded as one of the basic determinants of long run sustainable growth of a country. Therefore it is important to have an understanding of relative positions of countries in terms of competitiveness and determinants of competitive ability. This study aims to reveal the standing of Turkey in a group of countries and analyze determinants of competitive ability. The competitive industrial performance (CIP) index, taken to be an indicator of relative competitive ability, has been calculated for a sample of 33 countries for years 1985, 1990, 1998 and 2002. Panel data methods then have been employed to reveal sources of competitive ability. Conducted analysis reveals Turkish manufacturing industry to be lagging behind many of the sample countries and presents a grim picture for sustainable development in medium and long run.
\end{abstract}

Keywords: manufacturing industry, competition, technological progress, sustainable economic growth

\section{INTRODUCTION}

Competitiveness is regarded as the main condition for existence in the new global market and competitive environment which are shaped by knowledge economies. Success of a country in the process of competition is closely related 
to the degree at which it can simultaneously increase the real incomes of it's citizens and produce internationally demanded goods and services in accordance with free and fair market conditions. In addition, a country's or a region's competitiveness includes the provision of high living standards and employment opportunities. Definition of competitiveness also includes evasion of unsustainable foreign deficits and risking the welfare of future generations (European Competitiveness Report, 2004).

The question of where competitiveness of a country is actually embedded has little room for debate. The common understanding is that competitive ability of a country originates in the manufacturing industry for manufacturing industry is the real part of the economy and is the prime creator of value added and jobs in many economies. And higher is the technical complexity of processes and products in manufacturing industry, higher is the value added created. At this point manufacturing industry becomes the focus of policy and research for sustainable development.

Manufacturing industry is regarded as one of the most important economic activities that enable sustainable competitiveness and economic growth (UNIDO 2002- 2003:11). Therefore identification of relative standings of countries in terms of competitiveness arises as an important research question. The aim of this paper is to analyze the relative standings of a sample of countries by using the CIP (Competitive Industrial Performance) index and examine drivers of competitiveness, as measured by CIP, making use of panel data analysis methods.

The study progresses as follows: second part explains the calculation of CIP (Competitive Industrial Performance) index and the drivers behind the index. A brief description of the data used for calculation of CIP index is also provided. Section 3 presents the calculated performance indicators fro the sample countries and CIP index results. Section 4 presents an overview of the drivers data collected to create a panel data set and addresses the related econometric concerns on estimation. Section 5 presents the econometric results. Conclusions and comments on policy implications are presented in Section 6.

\section{CIP INDEX AND ITS DRIVERS}

The analysis conducted in this study actually consists of two layers. The first part is related to the calculation of CIP index and the picture provided by the index rankings. Second part consists of econometric analysis and makes use of available panel data. Forming the core of sections 2 and 3, Competitive Industrial Performance Index (CIP) shows the performances of the countries on producing and exporting manufactured goods in a competitively. It is an amalgam of four basic indicators. The first two of these indicators are about industrial capacity whereas the other two provide intuitions on technological complexity of manufacturing industry (UNIDO, 2002). 
CIP index is frequently used by international institutions and its applications focus on international comparison of manufacturing industry. The CIP index measures the ability of countries to produce and export manufactures competitively (UNIDO, 2002). The index is derived by transforming four data items in to performance indicators and then by taking their average. The four indicators mentioned before are as follows:

- $\quad$ Performance indicator 1: This indicator is composed of manufacturing industry value added per capita statistics. This indicator helps to observe the contribution of the manufacturing sector to the development, rather than growth, of a country by focusing on a limited measure of individuals' gains from manufacturing industry.

- Performance indicator 2: This indicator consists of manufacturing industry exports per capita statistics. This indicator is related to the competitiveness of the industry in international markets.

- $\quad$ Performance indicator 3: The ratio of medium and high technology industries' value added to the aggregate manufacturing industry value added is the basis of this indicator. The higher rates of medium and high - tech industries' value added in whole manufacturing value added mean that the country's technological development level and industrial competitiveness are high. Technological intensity of an industry is very important in terms of creation and dissemination of innovations and future competitiveness, for it carries the potential for feedbacks that may trigger further technical improvements.

- $\quad$ Performance indicator 4: The last indicator is based on the ratio of medium and high - tech industries' exports to the total manufacturing industry exports. This indicator provides information about the competitive power of technologically complex goods produced by a country's manufacturing industry in international markets.

These four performance indicators are calculated by using the formula below:

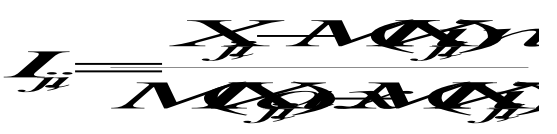

Here, $X_{j, i}$ represents the $j^{\text {th }}$ statistical value of $i^{\text {th }}$ country for the related index. The values of calculated indicators range between 0 and 1 where 0 represents the worst case and 1 stands for the case where the relevant data is highest. The logic of the indicator can be viewed as forming a line segment with length equal to the distance between best and worst case countries. Then, all the countries are placed along the line segment to reveal their relative standings. 
CIP index is then calculated as the average of the four performance indicators, presenting an overall view of a country's manufacturing industry's relative standing. The CIP index is capable of taking into account competitiveness not only in terms of technological content of manufacturing industry but also is capable to account for how beneficial it is for the country's citizens, for it takes in to account per capita value added values as well. Given that success in competitiveness is defined to include improvements in the well being of citizens, the index is ideal for the study's aim. It not only enables uncovering relative standings of countries but also does a good job of embracing the concept of competitiveness as defined above.

Moreover a number of drivers of CIP index are identified by UNIDO Industrial Development reports for years 2005 and 2002/2003. These drivers are assumed to contribute to competitiveness of a country and thus can be taken as determinants of the index. Among those drivers are skills, foreign direct investment (FDI) and modern infrastructure.

Skills have always been important for industrial performance. But they have become even more crucial because of the explosive growth of the weightless economy and the high information content of industrial activities. It is difficult to quantify a country's stock of industrial skills. Few countries publish data on people's skills by discipline. And even if such data existed, it would be impossible to estimate levels of relevant, up-to-date skills. A common method in existing literature is to approximate existing human capital by education data. The logical connection runs causality from education to skills; a better educated population will be more capable of displaying advanced skills and would be more capable of complex production methods. This would lead to ease of creation of high value added goods.

However, it should be kept in mind that measures like current education enrollments at the primary, secondary and tertiary levels have two main drawbacks. First, they ignore on-the-job learning-experience and trainingwhich in many countries is a major source of skill formation. Second, enrolment data do not take into account the significant differences across countries in education quality, completion rates and relevance to industrial needs. Given the lack of sources for appropriate data, education figures are used despite the stated shortcomings. Such an approach will also be adopted here.

As a second driver, FDI is an important way of transmitting skills, knowledge and technology to developing countries. Transnational corporations, generally the leading innovators in their industries, are engaging in more and more technology transfer. This can be taken to be reflecting the rising cost and pace of technical progress and the reluctance of innovators to sell valuable technologies to independent firms. Transnational corporations also provide capital, skills, managerial know-how and access to diverge markets.

The ideal FDI measure for assessing industrial performance would be inflows 
into manufacturing (and within that, into domestic and export production). But this kind of disaggregation is generally not possible: for most countries the only available measures are inward FDI flows and stocks.

The final driver considered here is the modern infrastructure. Compared to traditional infrastructure, which includes items like roads, railways, power lines etc, modern infrastructure is defined to include a more knowledge and communication oriented structure. Any item that enables creation and transfer of knowledge can be considered within modern infrastructure. The point is choosing the data to represent such knowledge. Some examples would include number of internet users, number of PCs or internet serves and existing telecommunication lines.

The ease of communication presented by such an infrastructure enables transfer of knowledge and raises possibility to spread information, know-how and innovations at a faster rate. It would be easier to acquire information and the difficulty of creating new knowledge would decrease significantly. This would enable not only production but also design of goods with high technology. Hence, value added creation will increase and the country will become capable of not only selling successfully at the international market but also be able to maintain high living standards for citizens.

Data issues regarding drivers will be discussed in more detail under the econometric model section. For the sole purpose of calculation of CIP index, necessary data have been collected from UNIDO Industrial Development Report 2002/2003 (for the years of 1985 and 1998) and UNIDO Industrial Development Report 2005 (for the years of 1990 and 2002). The data have been used firstly to form the performance indicators and secondly to calculate the CIP index. The sample includes 33 countries; namely, Argentina, Australia, Austria, Belgium-Luxembourg, Brazil, Canada, Czechoslovakia, Denmark, Finland, France, Germany, Greece, Hungary, Iceland, Ireland, Italy, Japan, Korea, Mexico, Netherlands, New Zealand, Norway, Poland, Portugal, Singapore, Spain, Sweden, Switzerland, Taiwan, Thailand, Turkey, UK and US. Due to lack of data, it has been necessary to merge Belgium with Luxembourg and Czech Republic with Slovakia.

\section{PERFORMANCE INDICATOR RESULTS}

This section provides rankings of countries in terms of performance indicators. Presented below as Table 1 are the country ranks according to the first performance indicator calculated by using manufacturing value added of the selected countries. Japan and Switzerland are consistently leading in terms the first indicator. The high places are occupied by the rich OECD members. The notable exception is Ireland, a common example for growth practices. It has risen to 5th place in 2002 from 19th place in 1985. 
Similar dynamics are presented by Singapore and Taiwan, albeit with less success. Korea arises as another success story, rising from 24th place to 13th place in about 20 years. Latin America countries occupy low ranks and share low ranks with East European countries like Czechoslovakia, Hungary and Poland. Outlook is grim for Turkey for it has not been possible to rise above rank 30 in the considered time period.

Presented next on Table 2 are performance indicator ranks of indicator 2 which is based on exports per capita for manufacturing industry. Ireland once more displays a striking performance but Singapore consistently occupies the first place for all considered years. Belgium-Luxembourg also consistently occupies the top ranks. These countries are followed by other OECD countries that are known for their high income levels. Latin America countries once more occupy the low ranks. One interesting point is that Mexico has risen to rank 25 in 1998, a jump of 7 ranks from year 1990. This can be due to the North America Free Trade Agreement, signed in 1992 by USA, Canada and Mexico. It is possible that reallocation of production processes to Mexico has triggered an increase in the country's export capability.

South East Asian countries in the sample do not display increases in per capita exports but on average do slightly better than East European Countries. Turkish case is once more discouraging, occupying the 29th place in 1985 but falling to 31st place in 2002. Doing worse than Turkey are Brazil and Argentina with ranks 33 and 32 respectively. Greece, Poland and Thailand perform slightly better than Turkey in year 2002 and occupy ranks 30, 29 and 28. Faring unexpectedly poorly according to this indicator is the USA. It is possible that the low ranks of USA are due to relatively large population, leading to a low per capita export value, and domestic market oriented production. 
Table 1: Performance Indicator 1 Rankings

\begin{tabular}{|c|c|c|c|c|}
\hline & 1985 & 1990 & 1998 & 2002 \\
\hline Argentina & 22 & 27 & 25 & 28 \\
\hline Australia & 15 & 22 & 22 & 23 \\
\hline Austria & 9 & 5 & 9 & 7 \\
\hline Bel-Lux & 13 & 4 & 12 & 6 \\
\hline Brazil & 28 & 28 & 28 & 31 \\
\hline Canada & 7 & 17 & 17 & 16 \\
\hline Czech-Slov. & NA & 25 & 24 & 27 \\
\hline Denmark & 11 & 7 & 10 & 10 \\
\hline Finland & 6 & 6 & 6 & 3 \\
\hline France & 8 & 10 & 11 & 12 \\
\hline Germany & 5 & 3 & 5 & 8 \\
\hline Greece & 27 & 26 & 27 & 26 \\
\hline Hungary & 25 & 29 & 26 & 25 \\
\hline Iceland & NA & 16 & NA & 19 \\
\hline Ireland & 19 & 18 & 3 & 5 \\
\hline Italy & 12 & 15 & 14 & 17 \\
\hline Japan & 3 & 1 & 2 & 2 \\
\hline Korea & 24 & 23 & 23 & 13 \\
\hline Mexico & 29 & 30 & 29 & 32 \\
\hline Netherlands & 17 & 12 & 15 & 14 \\
\hline New Zealand & 18 & 21 & 21 & 22 \\
\hline Norway & 10 & 14 & 16 & 18 \\
\hline Poland & 26 & 32 & 30 & 30 \\
\hline Portugal & 23 & 24 & 19 & 24 \\
\hline Singapore & 16 & 9 & 4 & 9 \\
\hline Spain & 21 & 20 & 20 & 21 \\
\hline Sweden & 4 & 8 & 8 & 4 \\
\hline Switzerland & 1 & 2 & 1 & 1 \\
\hline Taiwan & 20 & 19 & 18 & 15 \\
\hline Thailand & 31 & 31 & 32 & 29 \\
\hline Turkey & 30 & 33 & 31 & 33 \\
\hline United Kingdom & 14 & 13 & 13 & 20 \\
\hline United States & 2 & 11 & 7 & 11 \\
\hline
\end{tabular}

Source: Authors' calculations 
Çağaçan DEĞER, Burcu TÜRKCAN and Neşe KUMRAL

Table 2: Performance Indicator 2 Rankings

\begin{tabular}{|c|c|c|c|c|}
\hline & 1985 & 1990 & 1998 & 2002 \\
\hline Argentina & 28 & 30 & 29 & 32 \\
\hline Australia & 24 & 25 & 24 & 26 \\
\hline Austria & 12 & 7 & 9 & 9 \\
\hline Bel-Lux & 2 & 2 & 3 & 3 \\
\hline Brazil & 27 & 33 & 31 & 33 \\
\hline Canada & 9 & 12 & 11 & 10 \\
\hline Czech-Slov. & NA & 20 & 18 & 20 \\
\hline Denmark & 8 & 9 & 8 & 8 \\
\hline Finland & 7 & 8 & 7 & 7 \\
\hline France & 16 & 13 & 13 & 14 \\
\hline Germany & 11 & 10 & 10 & 12 \\
\hline Greece & 25 & 27 & 26 & 30 \\
\hline Hungary & 13 & 24 & 32 & 19 \\
\hline Iceland & NA & 26 & NA & 27 \\
\hline Ireland & 10 & 6 & 2 & 2 \\
\hline Italy & 17 & 15 & 15 & 15 \\
\hline Japan & 6 & 17 & 23 & 17 \\
\hline Korea & 19 & 21 & 17 & 18 \\
\hline Mexico & 30 & 32 & 25 & 25 \\
\hline Netherlands & 4 & 4 & 5 & 5 \\
\hline New Zealand & 21 & 19 & 22 & 23 \\
\hline Norway & 14 & 11 & 16 & 13 \\
\hline Poland & 26 & 29 & 28 & 29 \\
\hline Portugal & 23 & 18 & 20 & 22 \\
\hline Singapore & 1 & 1 & 1 & 1 \\
\hline Spain & 22 & 22 & 19 & 21 \\
\hline Sweden & 5 & 5 & 6 & 6 \\
\hline Switzerland & 3 & 3 & 4 & 4 \\
\hline Taiwan & 15 & 14 & 12 & 11 \\
\hline Thailand & 31 & 28 & 27 & 28 \\
\hline Turkey & 29 & 31 & 30 & 31 \\
\hline United Kingdom & 18 & 16 & 14 & 16 \\
\hline United States & 20 & 23 & 21 & 24 \\
\hline
\end{tabular}

Source: Authors' calculations. 
Table 3: Performance Indicator 3 Rankings

\begin{tabular}{|c|c|c|c|c|}
\hline & 1985 & 1990 & 1998 & 2002 \\
\hline Argentina & 27 & 27 & 29 & 25 \\
\hline Australia & 21 & 20 & 16 & 23 \\
\hline Austria & 16 & 21 & 20 & 19 \\
\hline Bel-Lux & 14 & 14 & 17 & 16 \\
\hline Brazil & 11 & 19 & 11 & 18 \\
\hline Canada & 17 & 18 & 18 & 13 \\
\hline Czech-Slov. & 18 & 11 & 23 & 14 \\
\hline Denmark & 19 & 23 & 19 & 17 \\
\hline Finland & 22 & 25 & 13 & 15 \\
\hline France & 15 & 15 & 14 & 21 \\
\hline Germany & 2 & 2 & 4 & 8 \\
\hline Greece & 31 & 30 & 31 & 31 \\
\hline Hungary & 5 & 16 & 24 & 20 \\
\hline Iceland & NA & 32 & NA & 33 \\
\hline Ireland & 12 & 9 & 3 & 2 \\
\hline Italy & 9 & 7 & 15 & 24 \\
\hline Japan & 3 & 3 & 2 & 3 \\
\hline Korea & 20 & 13 & 9 & 6 \\
\hline Mexico & 26 & 26 & 30 & 27 \\
\hline Netherlands & 10 & 8 & 10 & 9 \\
\hline New Zealand & 28 & 29 & 26 & 26 \\
\hline Norway & 13 & 12 & 21 & 12 \\
\hline Poland & 23 & 24 & 25 & 30 \\
\hline Portugal & 29 & 31 & 32 & 32 \\
\hline Singapore & 1 & 1 & 1 & 1 \\
\hline Spain & 24 & 22 & 22 & 22 \\
\hline Sweden & 7 & 10 & 8 & 4 \\
\hline Switzerland & 8 & 6 & 5 & 10 \\
\hline Taiwan & 25 & 17 & 12 & 11 \\
\hline Thailand & 32 & 33 & 27 & 28 \\
\hline Turkey & 30 & 28 & 28 & 29 \\
\hline United Kingdom & 6 & 5 & 7 & 5 \\
\hline United States & 4 & 4 & 6 & 7 \\
\hline
\end{tabular}

Source: Authors' calculations. 
Presented on Table 3 are rankings of countries according to the third performance indicator based on the ratio of medium and high technology sectors in total manufacturing value added. The consistent success of Ireland and Singapore is once more observed. Japan is also a winner in terms of the third indicator. The OECD countries once more occupy most of the high ranks. However, some interesting dynamics can be observed. Italy displays a considerable worsening in terms of technology content in production, falling to 24th position in 2002 from 9th position in 1985. Korea, on the other hand, displays considerable rank increase from 1985 to 2002, moving up to 6th position. Hungary is another country that suffers serious rank losses and moves to 20th position in 2002 from 4th position in 1985. Argentina and Mexico perform blow average but Brazil displays above average performance. Turkey once more occupies some of the lowest

The volatilities in Table 3 imply that in the last 20 years, the world has experienced considerable shifts in allocation of medium and high technology across countries. It is unfortunate that Turkey has not moved to higher ranks during this process. It is possible that Turkey has not managed to benefit from shifts in global reallocation of production processes and has not been able to attract or create the ability to produce medium and high technology goods. The situation bodes ill for the country, implying that a gap between sample countries and Turkey is now in existence and efforts are needed to close this gap.

Based on share of medium and high technology sectors in manufacturing industry exports, the 4th performance indicator gives rise to the rankings presented in Table 4. It is interesting to note that Ireland is not a success story in this case; actually, Ireland falls to 19th position in 2002 from 13th in 1985. One other interesting point is that some of the relatively more developed countries display losses in ranks. Within the considered time period, Austria falls from 9th position to 16th, Norway falls all the way to 30th position, and Switzerland falls to 10th position after losing 6 ranks. Relatively milder falls are observed for other well developed countries as well.

On the other side of the coin are position gains by other countries. Hungary rises to 7th place whereas Mexico displays a surprising rise to 3rd position. From the 14th position in 1985, Singapore rises to 2 nd position in 2002. Taiwan also follows a similar path. It is possible that as production of relatively high technology goods re-allocates to less developed countries, probably due to lower labor costs, these countries become exporters of such goods. This may appear to be a contradiction for these countries are not among the countries that have very high shares of medium and high technology sectors in manufacturing value added. Such a contradiction may be explained away as follows: 
Table 4: Performance Indicator 4 Rankings

\begin{tabular}{|l|c|c|c|c|}
\hline & 1985 & 1990 & 1998 & 2002 \\
\hline Argentina & 28 & 29 & 28 & 29 \\
\hline Australia & 30 & 27 & 31 & 28 \\
\hline Austria & 9 & 12 & 19 & 16 \\
\hline Bel-Lux & 15 & 15 & 21 & 25 \\
\hline Brazil & 23 & 25 & 26 & 24 \\
\hline Canada & 11 & 9 & 20 & 18 \\
\hline Czech-Slov. & $\mathrm{NA}$ & $\mathrm{NA}$ & 14 & 23 \\
\hline Denmark & 19 & 17 & 24 & 20 \\
\hline Finland & 20 & 23 & 18 & 21 \\
\hline France & 7 & 8 & 11 & 11 \\
\hline Germany & 2 & 3 & 5 & 5 \\
\hline Greece & 27 & 31 & 30 & 32 \\
\hline Hungary & 31 & 24 & 10 & 7 \\
\hline Iceland & $\mathrm{NA}$ & 21 & $\mathrm{NA}$ & 14 \\
\hline Ireland & 13 & 14 & 15 & 19 \\
\hline Italy & 12 & 18 & 16 & 22 \\
\hline Japan & 1 & 1 & 1 & 1 \\
\hline Korea & 8 & 13 & 8 & 9 \\
\hline Mexico & 6 & 5 & 3 & 3 \\
\hline Netherlands & 21 & 20 & 17 & 17 \\
\hline New Zealand & 29 & 32 & 32 & 33 \\
\hline Norway & 24 & 22 & 29 & 30 \\
\hline Poland & 16 & 19 & 25 & 26 \\
\hline Portugal & 22 & 28 & 23 & 27 \\
\hline Singapore & 14 & 7 & 2 & 2 \\
\hline Spain & 5 & 11 & 13 & 13 \\
\hline Sweden & 18 & 6 & 12 & 12 \\
\hline Switzerland & 16 & 6 & 10 \\
\hline Taiwan & 26 & 22 & 15 \\
\hline Thailand & 30 & 27 & 31 \\
\hline Turkey & & 7 & 6 \\
\hline United Kingdom & 25 & 4 & 4 \\
\hline United States & 16 & & \\
\hline Source: Authors & & 9 & 8 \\
\hline
\end{tabular}

Source: Authors' calculations.

Consider a developing country that does not produce very complex goods and thus has low shares of medium and high technologies in manufacturing value added and exports. Now consider a reallocation of production processes to 
similar developing countries. These countries will now be producing relatively more complex goods, but such production may account for a small portion of total value added created in the economy. If the country is initially exporting simple goods that have low value added, introduction of medium and high technology goods which have more value added would distort the export structure in favor of complex goods. This would be even truer if the country had previously been producing for mostly the local market and had relatively low exports to begin with. Such a dynamic would be even more logical if one assumes or believes that such reallocation of production processes aims to use developing countries as production base for goods to be sold in developed countries.

However, such analysis would not curtail Turkey's lagging position; even though Turkey occupies the 25th place in year 1985, the rank has fallen to 31 in year 2002. This can be taken to mean that Turkey has not been able to benefit from a reallocation of production processes and the opportunity to gain from the technology transfers provided by such reallocations appear to have been missed.

Having obtained the performance indicator values, it is now possible to calculate the CIP index values for the selected countries. The rankings implied by the calculated index values are available on Table 5 . It should be noted that the rows of this table are ordered according to rank in year 2002.

Singapore, Switzerland and Japan share the top places in the CIP index rankings. Ireland rises from 15th place to 2 nd in the time period under focus. Finland, Korea and Taiwan are other examples of improvement. Latin America countries display below average performance whereas Southeast Asian countries display at least slight improvements in rank, as in the case of Thailand, or are consistent leaders, as is Singapore. The rankings also imply that France, Canada, Italy and Norway have become slightly less competitive during the last 20 years. Hungary is one of the countries that slightly improve in rank, but Poland and Czechoslovakia have recessed to lower ranks. Finally, Turkey has one of the lowest ranks for all the four years and has slowly, but steadily fallen to the 32nd position in 2002. 
Table 5: CIP Rankings of Countries

\begin{tabular}{|l|c|c|c|c|}
\hline CIP & $\mathbf{1 9 8 5}$ & $\mathbf{1 9 9 0}$ & $\mathbf{1 9 9 8}$ & $\mathbf{2 0 0 2}$ \\
\hline Singapore & 3 & 1 & 1 & 1 \\
\hline Ireland & 15 & 13 & 4 & 2 \\
\hline Switzerland & 2 & 3 & 2 & 3 \\
\hline Japan & 1 & 2 & 3 & 4 \\
\hline Sweden & 6 & 6 & 6 & 5 \\
\hline Germany & 4 & 4 & 5 & 6 \\
\hline Bel-Lux & 7 & 5 & 10 & 7 \\
\hline United States & 5 & 7 & 7 & 8 \\
\hline Finland & 14 & 14 & 9 & 9 \\
\hline Korea & 19 & 19 & 15 & 10 \\
\hline United Kingdom & 10 & 8 & 8 & 11 \\
\hline Taiwan & 18 & 18 & 13 & 12 \\
\hline Netherlands & 9 & 9 & 11 & 13 \\
\hline Austria & 12 & 10 & 14 & 14 \\
\hline Denmark & 16 & 12 & 17 & 15 \\
\hline France & 11 & 11 & 12 & 16 \\
\hline Canada & 8 & 15 & 18 & 17 \\
\hline Hungary & 21 & 22 & 21 & 18 \\
\hline Italy & 13 & 16 & 16 & 19 \\
\hline Spain & 20 & 20 & 19 & 20 \\
\hline Norway & 17 & 17 & 22 & 21 \\
\hline Mexico & 22 & 21 & 23 & 22 \\
\hline Czech-Slov. & $\mathrm{NA}$ & $\mathrm{NA}$ & 20 & 23 \\
\hline Brazil & 24 & 25 & 24 & 24 \\
\hline Australia & 25 & 23 & 26 & 25 \\
\hline Thailand & 31 & 32 & 28 & 26 \\
\hline Iceland & $\mathrm{NA}$ & 26 & $\mathrm{NA}$ & 27 \\
\hline Portugal & 26 & 27 & 25 & 28 \\
\hline Argentina & 28 & 29 & 30 & 29 \\
\hline Poland & 23 & 24 & 27 & 30 \\
\hline New Zealand & 27 & 28 & 29 & 31 \\
\hline Turkey & 29 & 31 & 31 & 32 \\
\hline Greece & 30 & 30 & 32 & 33 \\
\hline Source Auts' & & & & \\
\hline
\end{tabular}

Source: Authors' calculations. 


\section{DRIVERS' DATA AND ECONOMETRIC MODEL}

Country coverage of the collected driver data is 33 countries; specifically Argentina, Australia, Austria, Belgium-Luxembourg, Brazil, Canada, Czechoslovakia, Denmark, Finland, France, Germany, Greece, Hungary, Iceland, Ireland, Italy, Japan, Korea, Mexico, Netherlands, New Zealand, Norway, Poland, Portugal, Singapore, Spain, Sweden, Switzerland, Thailand, Taiwan, Turkey, United Kingdom and United States. Due to lack of data, Belgium and Luxembourg have been treated as a single entity. Same situation holds for Czech Republic and Slovakia as well.

The econometric part of this study makes heavy use of data obtained from International Measures of Schooling Years and Schooling Quality Dataset (Barro and Lee, 2000: 24-32 ) and World Bank's WDI (World Development Indicators) Database. Foreign direct investment is taken to be one of the drivers of CIP and is generally regarded to be a vehicle of technology transfer to manufacturing industry. To account for such transfers, net FDI inflow as percentage of GDP and net current FDI inflow have been obtained from WDI. The net current FDI inflow has been turned to real units by making use of United States GDP deflator series that takes year 2000 as the base year. The deflator is from WDI as well. The data related to FDI is generally available for all sample countries between years 1975 and 2005. The noticeable exceptions are Argentina for years 1975 and 1976, Czechoslovakia for 1975 to 1989, Poland for 1975 to 1984 and Switzerland for 1975 to 1982.

One other item to be considered as a driver of CIP is the existing modern infrastructure. Upon defining modern infrastructure to include technological components, it becomes necessary to include items like number of internet users or availability of personal computers. However, data on such items is not available for past decades, simply because such items did not exist back then. In order to account for relatively technical infrastructure differences across countries, two items of data have been chosen: fixed line and mobile phone subscribers per 100 people and telephone mainlines per 100 people. These two items are available through WDI dataset for all countries in the sample with 13 missing observations for various in the case of fixed and mobile line subscribers' data.

The last major item concerns education as a representative of capabilities of the labor force. To account for skills of the labor force, a human capital line of thought has been adopted. Thus education variables have been the focus as the last driver of CIP. Percentage of primary school attained, percentage of primary school completed, percentage of secondary school attained, percentage of secondary school completed, percentage of higher school attained and percentage of higher school completed have been taken from Barro-Lee dataset. The mentioned percentages are of the total population, where total population consists of people aged 25 and above. Average schooling years, average years of primary schooling, average years of 
secondary schooling and average years of higher schooling in total population are also taken from the same dataset. The data covers all countries except Belgium-Luxembourg, forcing the country out of the econometric considerations. The coverage of the data is also lacking in time dimension; it is available for years 1975, 1980, 1985 and 1990 only.

Finally, the dependent variable is the CIP with data available for years 1985 , 1990, 1998, and 2002. Thus the existing dataset of the study is actually a panel that focuses on 4 time periods and 33 countries, if one includes BelgiumLuxembourg.

The existing panel dataset raises the need for appropriate estimation techniques. Consider a panel dataset of $\mathrm{N}$ cross section units and $\mathrm{T}$ time dimensions, be it years or any other unit. In most general terms, the estimation of a linear equation making use of a panel dataset can be summarized by the following:

$Y=\beta_{0}+X \beta+e$

(2)

where $Y$ is the NTx1 vector of independent variable and $X$ is the NTxk matrix of $\mathrm{k}$ independent variables. The $\beta$ is the $\mathrm{kx} 1$ vector of slope coefficients to be estimated; $\beta_{0}$ is the intercept term that is assumed to be common for all cross section units and time periods. Regarding the NTx 1 error term, e, it is assumed that $E\left(e_{i t}\right)=0, E\left(e_{i t}{ }^{2}\right)=\sigma^{2}$ (i.e. variance is constant) and $E\left(e_{i t} e_{j s}\right)=0$ for all i,j and $\mathrm{t} \neq \mathrm{s}$ and $\mathrm{E}\left(\mathrm{e}_{\mathrm{it}} \mid \mathrm{X}\right)=0$ for all $\mathrm{i}, \mathrm{t}$. These assumptions imply that the stated model can be estimated by ordinary least squares (OLS) technique (Erlat, 2008).

One interesting possibility in panel data is to assume that each cross section unit has unique properties that can be introduced into the model separately. This approach introduces different intercepts for each cross section unit through use of dummy variables. Such a model is called a one way model and can be summarized as

$Y=\beta_{0}+D_{\delta} \delta+\beta X+e$

where $D_{\delta}$ is a NTxN matrix of stacked dummy variables. Above formulation assumes that each cross section will have an intercept that varies from a common intercept, $\beta_{0}$, by the amount $\delta_{i}$. These variations or effects can take two forms; they can be fixed or random.

In case of fixed effects, direct estimation of the model by OLS is not possible due to the perfect collinearity introduced by the $D_{\delta}$ dummies. The estimation procedure in this case includes a transformation that wipes out the individual 
effects to obtain an estimator of $\beta$ vector (Baltagi, 1995:10-11). One candidate transformation turns the data into deviation from cross section means and thus leads to the within estimator of $\beta$ (Johnston and DiNardo, 1997: 398). Identification of the common intercept and the deviations is relatively easy, given the between estimator (Erlat, 2008: 12), and a joint significance test can be conducted to determine the significance of the fixed effects. If the fixed effects are found to be insignificant, one can simply use pooled OLS approach.

Alternative specification assumes that the effects summarized by $\delta$ are random variables. This formulation leads to the random effects model where $\delta$ effects are now part of the error term. Therefore, assumptions on their distribution are in order. Firstly, $E\left(\delta_{i}\right)=0$ and $E\left(\delta_{i}{ }^{2}\right)=\sigma^{2}{ }_{\delta}$ for all $i$; also, $E\left(\delta_{i} \delta_{j}\right)=0$ for all $i \neq j$ whereas $E\left(\delta_{i} e_{i t}\right)=0$ for all $i, j$ and $t$ (Hsiao, 2003: 34). And last, but certainly not the least, $E\left(\delta_{i} \mid X\right)=0$ for all $i$ (Erlat, 2008: 13).

We can think of the random effects model to have a composite error term, $\varepsilon_{\mathrm{it}}=$ $\delta_{i}+e_{i t}$. Given the distribution properties of e and $\delta$, it can be shown that the composite error term has the following properties: $E\left(u_{i t}\right)=0, E\left(u_{i t}{ }^{2}\right)=\sigma^{2}{ }_{\delta}+\sigma^{2}$ and $E\left(u_{i t} \mid X\right)=0$ while $E\left(u_{i t} u_{j s}\right)=0$ for all $i=j$ and $t \neq s(E r l a t, 2008: 13$; Greene, 2003:294). It should be noted that the $\delta$ term introduces a correlation among error terms of the same cross section unit but error terms are not correlated across cross section units (Hsiao, 2003: 35). Such correlations inspire use of generalized least squares (GLS) approach to estimate the random effects model. The construction of appropriate transformation is based on the estimation of variances $\sigma_{\delta}^{2}$ and $\sigma^{2}$; the method is due Swamy and Arora (1972).

Ignoring the differing intercepts of different cross section units would lead to biased OLS estimation. As compared to pooled OLS, fixed effects estimator would be immune to such bias. However, significant cross section specific effects may be correlated to the composite error term and may lead to biased GLS estimates (Kennedy, 2003: 305-306). Thus it is necessary to test if the assumption $\mathrm{E}(\mathrm{u} \mid \mathrm{X})=0$ holds. A most common procedure to test this is by Hausman (1978). The test is based on the idea that when the stated assumption does not hold, within estimator of the fixed effect model is consistent whereas GLS estimator of the random effect model becomes inconsistent. The proposed test makes use of the difference between these two estimators (Baltagi, 1995: $68)$.

\section{ECONOMETRIC RESULTS}

Since current competitiveness should be determined by previous occurrences in the economy, the considered model includes lagged values of independent variables. However, it is necessary to reconcile the CIP data and education data available. The education data is available for years 1975, 1980, 1985 and 1990. CIP is available for years 1985, 1990, 1998 and 2002. These dates imply two lags practically applicable; a 5 year lag or a 10 year lag for education related data.

If a lag of 5 years is selected, CIP for 1985 will match education data for 1980 and 
CIP data for 1990 will match the education data for year 1985. However, the education data for 1990 will have to be used for the 1998 CIP data, assuming that 1990 data is a good indicator for education in 1993. Also, there will not be matching education data for the year 2002. This would lead to a loss in time dimension of the panel data. In order to avoid this loss, a lag of 10 years has been adopted. Therefore, 1985, 1990, 1998 and 2002 CIP data are matched with 1975, 1980, 1985 and 1990 education data respectively. Implicit here is the assumption that education data for 1985 and 1990 are good proxies for corresponding education data for 1988 and 1992.

Basically, the model is planned to include three independent variables; one of them an indicator of education and hence human capital, the second an indicator of modern infrastructure and the last a representative of FDI flows. The data, as explained above, exists. Actually, there is a surplus of variables to pick from. Therefore, two points are of concern at this point: which independent variables will be used and which lags will be chosen for these independent variables?

The last problem is actually partially solved by data restrictions: education related data have to have a lag of 10 years. Trial and error by estimation of a considerable number of models has led to the complete solution and the important result that all the trials point to significant cross-section specific effects. The process also has eliminated the data on fixed line and mobile phone subscribers per 100 people and real FDI flow as determinants of CIP by identifying them as statistically insignificant at all lags. The fine tuning of the adopted methodology will be presented here. The following table of data and related abbreviations has been provided to make the discussion more comprehensible.

Table 6: Variables and Abbreviated Names

\begin{tabular}{|l|l|}
\hline Average schooling years in the total population & sch_aver \\
\hline Average years of higher schooling in the total population. & sch_aver_hgh \\
\hline Average years of primary schooling in the total population & sch_aver_pr \\
\hline Average years of secondary schooling in the total population. & sch_aver_sec \\
\hline CIP & cip \\
\hline Foreign direct investment, net inflows (\% of GDP) & fdi_gdp \\
\hline Percentage of "higher school attained" in the total pop & sch_hgh_a \\
\hline Percentage of "higher school complete" in the total pop. & sch_hgh_c \\
\hline Percentage of "no schooling" in the total population & sch_no \\
\hline Percentage of "primary school attained" in the total pop. & sch_pr_a \\
\hline Percentage of "primary school complete" in the total pop & sch_pr_c \\
\hline Percentage of "secondary school attained" in the total pop & sch_scnd_a \\
\hline Percentage of "secondary school complete" in the total pop & sch_scnd_c \\
\hline Telephone mainlines (per 100 people) & telep_main_100 \\
\hline
\end{tabular}


The most generic form of the model that is the basis of the analysis is as follows:

$\operatorname{cip}_{i t}=\beta_{0}+\beta_{1}$ fdi_gdp $_{\mathrm{t}-4}+$ telep_main_100 $100_{\mathrm{t}-3}+$ EDUCATION $_{\mathrm{t}-10}$

(4)

Regarding sign expectations, foreign direct investment inflows are expected to enable technological transfers and contribute to the competitiveness of manufacturing industry; thus a positive sign is expected for the related coefficient. Telephone mainlines per 100 people is taken as an indicator of technical complexity of the relevant country. A higher complexity is expected to contribute to higher competitiveness, leading to a positive sign expectation. Higher education of the population would enable use of more complex production techniques and enable production of goods with higher value added. Thus a higher education level is expected to contribute to competitiveness and this should be revealed by a positive sign.

Table 7: Models List with Relevant Education Variable

\begin{tabular}{|l|l|}
\hline \multicolumn{1}{|c|}{ Model Name } & Education Variable \\
\hline Model 1 & sch_aver(t-10) \\
\hline Model 2 & sch_aver_hgh(t-10) \\
\hline Model 3 & sch_aver_pr(t-10) \\
\hline Model 4 & sch_aver_sec(t-10) \\
\hline Model 5 & sch_hgh_a(t-10) \\
\hline Model 6 & sch_hgh_c(t-10) \\
\hline Model 7 & sch_pr_a(t-10) \\
\hline Model 8 & sch_pr_c(t-10) \\
\hline Model 9 & sch_scnd_a(t-10) \\
\hline Model 10 & sch_scnd_c(t-10) \\
\hline Model 11 & sch_no \\
\hline
\end{tabular}

By adopting various education related variables from the above table, it is possible to introduce a number of models. These models are listed in Table 7 above. The pooled OLS, fixed effects and random effects estimation results of these models are presented in Table 8 below.

Presented on the second column from the right on Table 8, the F-test rejects the null hypothesis that fixed effects coefficients are jointly insignificant. The Hausman test, on the other hand, leads to the rejection of the null hypothesis that GLS estimator of random effects model is consistent. A fixed effects model is more preferable for it is not only consistent but also takes into account the existence of cross section specific intercepts. Note that this analysis holds for all the considered models.

Regarding significance of coefficients; FDI inflow coefficients are found to be positive and statistically significant for all models and the three estimation 
methods. Telephone mainlines per 100 people is statistically significant with positive sign for all models in case of pooled OLS. However, once cross section specific effects are taken into account, this variable turns insignificant for all but two of the models. The coefficient sign also turns negative as well.

The situation is much more complicated in the case of education variables. The case of model 11 should be considered separately for it uses percentage of no schooling in total population. As more people receive no education, the competitiveness of the country should decrease, creating a negative coefficient. The education coefficient expectation for model 11 is negative.

Returning to the evaluation of models; in the case of pooled OLS, all the models display statistically insignificant results regarding. These models use average years of high schooling, percentage of high school attainment and high school completion in total population, respectively. Models 7 and 8 display expected signs on education variables. These models use secondary and primary education. In the case of model 11 , where education variable measures no education in total population, the coefficient is negative.

These results imply dynamics contradictory with our expectations. As education level decreases from higher levels to primary level, sign on education variable turns positive but loses significance. This is emphasized by model 11 where the sign on education variable is negative, implying that as the portion of population without education increases, competitiveness falls.

Given such confusing results, it is fortunate that the F-test points to a fixed effects model. In fixed effects estimation, FDI is statistically significant with the expected positive sign. Telephone mainlines per 100 people has a negative effect in 10 of the considered models. These negative coefficients are significant only in the case of models 3 and 11 .

Regarding education, models 7,8 and 11 have statistically significant education coefficients with expected signs. These models correspond to the cases of primary school attainment ratio, primary school completion ratio and no schooling ratio. This can be taken to indicate that lower education levels correspond to higher competitiveness. Whenever the education coefficients are not significant, they are negative contrary to sign expectations.

Consider the random effects estimations as the final case. Foreign direct investment has the expected sign for all models. The coefficients for telephone mainlines are concentrated around the value zero for all the models and are all insignificant except for model 11. Education coefficients are no insignificant for all models other than model 7, 8 and 11. First two of these models refer to primary school attainment and completion. The last model refers to the case of no schooling and has a negative sign. 


\begin{tabular}{|c|c|c|c|c|c|c|c|c|c|c|c|}
\hline & fdi_gdp(-4) & $\begin{array}{c}\text { telep_main_1 } \\
00(-3)\end{array}$ & EDUC & fdi_gdp(-4) & $\begin{array}{c}\text { telep_main } \\
100(-3)\end{array}$ & EDUC & fdi_gdp $(-4)$ & $\begin{array}{c}\text { telep_main } \\
100(-3)\end{array}$ & EDUC & $\begin{array}{c}\text { Fixed } \\
\text { Effects Test }\end{array}$ & $\begin{array}{c}\text { Hausman } \\
\text { Test }\end{array}$ \\
\hline Model 1 & $\begin{array}{l}0.0142 \\
2.4535 \\
(0.0157) \\
\end{array}$ & $\begin{array}{c}0.0051^{* * *} \\
4.7355 \\
(0.0000) \\
\end{array}$ & $\begin{array}{l}-0.0065 \\
-0.7869 \\
(0.4330) \\
\end{array}$ & $\begin{array}{c}0.0073 \\
2.4596 \\
(0.0160) \\
\end{array}$ & $\begin{array}{l}-0.0013 \\
-1.5199 \\
(0.1323)\end{array}$ & $\begin{array}{c}0.0045 \\
0.3568 \\
(0.7221) \\
\end{array}$ & $\begin{array}{l}0.0061 \\
2.1407 \\
(0.0344) \\
\end{array}$ & $\begin{array}{l}-0.0006 \\
-0.7747 \\
(0.4401) \\
\end{array}$ & $\begin{array}{c}0.0072 \\
0.7871 \\
(0.4328) \\
\end{array}$ & 0.0000 & 0.0000 \\
\hline Model 2 & $\begin{array}{c}0.0137 \\
2.4183 \\
(0.0172)\end{array}$ & $\begin{array}{c}0.0059^{\star \star \star *} \\
6.0058 \\
(0.0000)\end{array}$ & $\begin{array}{l}-0.1762 \\
-2.3139 \\
(0.0225)\end{array}$ & $\begin{array}{c}0.0077 \\
2.6189 \\
(0.0105) \\
\end{array}$ & $\begin{array}{l}-0.0007 \\
-1.0104 \\
(0.3152)\end{array}$ & $\begin{array}{l}-0.0681 \\
-1.1053 \\
(0.2722)\end{array}$ & $\begin{array}{c}0.0064 \\
2.2696 \\
(0.0251)\end{array}$ & $\begin{array}{c}0.0002 \\
0.3646 \\
(0.7160) \\
\end{array}$ & $\begin{array}{l}-0.0746 \\
-1.3219 \\
(0.1888)\end{array}$ & 0.0000 & 0.0000 \\
\hline Model 3 & $\begin{array}{l}0.0144 \\
2.5080 \\
(0.0136)\end{array}$ & $\begin{array}{c}0.0049^{* \star *} \\
5.4891 \\
(0.0000)\end{array}$ & $\begin{array}{l}-0.0086 \\
-0.8931 \\
(0.3737)\end{array}$ & $\begin{array}{l}0.0070 \\
2.4662 \\
(0.0157)\end{array}$ & $\begin{array}{l}-0.0018^{* *} \\
-2.6805 \\
(0.0089)\end{array}$ & $\begin{array}{l}0.0555 \\
2.3761 \\
(0.0198)\end{array}$ & $\begin{array}{l}0.0060 \\
2.2140 \\
(0.0288)\end{array}$ & $\begin{array}{l}-0.0006 \\
-0.9650 \\
(0.3366)\end{array}$ & $\begin{array}{l}0.0204 \\
1.5457 \\
(0.1250)\end{array}$ & 0.0000 & 0.0000 \\
\hline Model 4 & $\begin{array}{c}0.0149 \\
2.5615 \\
(0.0117)\end{array}$ & $\begin{array}{c}0.0041^{* \star *} \\
3.4550 \\
(0.0008)\end{array}$ & $\begin{array}{c}0.0108 \\
0.5277 \\
(0.5987)\end{array}$ & $\begin{array}{c}0.0072 \\
2.4537 \\
(0.0162)\end{array}$ & $\begin{array}{l}-0.0004 \\
-0.4709 \\
(0.6389)\end{array}$ & $\begin{array}{l}-0.0246 \\
-1.1003 \\
(0.2744)\end{array}$ & $\begin{array}{c}0.0061 \\
2.1446 \\
(0.0341)\end{array}$ & $\begin{array}{c}-0.0002 \\
0.7933 \\
(0.9574)\end{array}$ & $\begin{array}{l}-0.0010 \\
-0.0535 \\
(0.9574)\end{array}$ & 0.0000 & 0.0000 \\
\hline Model 5 & $\begin{array}{l}0.0134 \\
2.3739 \\
(0.0193)\end{array}$ & $\begin{array}{c}0.0060^{* * *} \\
6.0801 \\
(0.0000)\end{array}$ & $\begin{array}{l}-0.0054 \\
-2.4355 \\
(0.0164) \\
\end{array}$ & $\begin{array}{c}0.0077 \\
2.60007 \\
(0.0110) \\
\end{array}$ & $\begin{array}{l}-0.0007 \\
-1.1011 \\
(0.2740) \\
\end{array}$ & $\begin{array}{l}-0.0019 \\
-1.1152 \\
(0.2680) \\
\end{array}$ & $\begin{array}{c}0.0062 \\
2.2233 \\
(0.0282) \\
\end{array}$ & $\begin{array}{c}0.0001 \\
0.2930 \\
(0.7700) \\
\end{array}$ & $\begin{array}{l}-0.0020 \\
-1.2310 \\
(0.2209) \\
\end{array}$ & 0.0000 & 0.0000 \\
\hline Model 8 & $\begin{array}{c}0.0145 \\
2.4812 \\
(0.0146) \\
\end{array}$ & $\begin{array}{c}0.0046^{\star \star \star} \\
5.5451 \\
(0.0000) \\
\end{array}$ & $\begin{array}{c}0.0001 \\
0.0715 \\
(0.9431)\end{array}$ & $\begin{array}{c}0.0075^{* *} \\
2.7019 \\
(0.0084) \\
\end{array}$ & $\begin{array}{l}-0.0003 \\
-0.4687 \\
(0.6405) \\
\end{array}$ & $\begin{array}{c}0.0037^{* *} \\
3.3916 \\
(0.0011)\end{array}$ & $\begin{array}{l}0.0066 \\
2.4741 \\
(0.0148)\end{array}$ & $\begin{array}{c}0.0003 \\
0.4952 \\
(0.6214) \\
\end{array}$ & $\begin{array}{l}0.0032^{* *} \\
3.1670 \\
(0.0020)\end{array}$ & 0.0000 & 0.0000 \\
\hline Model 9 & $\begin{array}{l}0.0144 \\
2.5019 \\
(0.0138)\end{array}$ & $\begin{array}{c}0.0041^{* \star *} \\
3.8030 \\
(0.0002)\end{array}$ & $\begin{array}{l}0.0008 \\
0.6157 \\
(0.5393)\end{array}$ & $\begin{array}{l}0.0073 \\
2.4937 \\
(0.0146)\end{array}$ & $\begin{array}{l}-0.0008 \\
-1.1359 \\
(0.2593)\end{array}$ & $\begin{array}{l}-0.0008 \\
-0.7919 \\
(0.4307)\end{array}$ & $\begin{array}{l}0.0060 \\
2.1446 \\
(0.0341)\end{array}$ & $\begin{array}{l}-0.0002 \\
-0.2866 \\
(0.7749)\end{array}$ & $\begin{array}{l}-0.0001 \\
-0.1222 \\
(0.9029)\end{array}$ & 0.0000 & 0.0000 \\
\hline Model 10 & $\begin{array}{l}0.0151 \\
2.6036 \\
(0.0105) \\
\end{array}$ & $\begin{array}{c}0.0039^{* * *} \\
3.5595 \\
(0.0005) \\
\end{array}$ & $\begin{array}{c}0.0019 \\
0.8704 \\
(0.3859) \\
\end{array}$ & $\begin{array}{c}0.0073 \\
2.4731 \\
(0.0154) \\
\end{array}$ & $\begin{array}{l}-0.0011 \\
-1.6394 \\
(0.1049) \\
\end{array}$ & $\begin{array}{c}0.0002 \\
0.1382 \\
(0.8904) \\
\end{array}$ & $\begin{array}{c}0.0063 \\
2.2073 \\
(0.0293) \\
\end{array}$ & $\begin{array}{l}-0.0005 \\
-0.7226 \\
(0.4714) \\
\end{array}$ & $\begin{array}{c}0.0011 \\
0.7976 \\
(0.4267) \\
\end{array}$ & 0.0000 & 0.0001 \\
\hline Model 11 & $\begin{array}{c}0.0151 \\
2.5231 \\
(0.0130) \\
\end{array}$ & $\begin{array}{c}0.0044^{\star * *} \\
4.2303 \\
(0.0000) \\
\end{array}$ & $\begin{array}{l}-0.0005 \\
-0.3702 \\
(0.7119) \\
\end{array}$ & $\begin{array}{c}0.0085^{* *} \\
2.9922 \\
(0.0036) \\
\end{array}$ & $\begin{array}{l}-0.0012^{* *} \\
-2.9390 \\
(0.0043)\end{array}$ & $\begin{array}{c}-0.0049^{* *} \\
-3.1162 \\
(0.0025)\end{array}$ & $\begin{array}{c}0.0076^{* *} \\
2.7963 \\
(0.0061) \\
\end{array}$ & $\begin{array}{l}-0.0011 \\
-1.9266 \\
(0.0565) \\
\end{array}$ & $\begin{array}{c}-0.0043^{* *} \\
-3.2808 \\
(0.0014) \\
\end{array}$ & 0.0000 & 0.0001 \\
\hline
\end{tabular}


It is possible to use fixed effects estimation results to obtain a relative standing of Turkey. Since the dummy variable coefficient estimates in a fixed effect model point to how different one country's intercept is from the others, checking the dummy coefficients on Turkey may be informative. Turkey's dummy variable coefficient values for all 11 models are presented in Table 9 below.

Table 9: Turkey’s Dummy Variable Coefficient for Considered Models

\begin{tabular}{|l|l|}
\hline Model 1 & -0.2744 \\
\hline Model 2 & -0.2981 \\
\hline Model 3 & -0.138 \\
\hline Model 4 & -0.3087 \\
\hline Model 5 & -0.2982 \\
\hline Model 6 & -0.2972 \\
\hline Model 7 & -0.2279 \\
\hline Model 8 & -0.2478 \\
\hline Model 9 & -0.3011 \\
\hline Model 10 & -0.2894 \\
\hline Model 11 & -0.1084 \\
\hline
\end{tabular}

It can be seen that the dummy has a negative coefficient for all considered models. This can be taken to imply that Turkey's intercept is lower than the average; specifically, Turkey's competitiveness is less than the group average.

The general impression obtained from econometric considerations is that FDI has a positive and significant effect on international competitiveness as measured by CIP. Even though pooled OLS results support the view that a technical infrastructure as measured by telephone mainlines per 100 people has a positive and significant effect on competitiveness of a country's manufacturing industry, this view is questioned by fixed effects and random effects estimation results.

It can be argued that a better measurement of modern infrastructure should be developed in order to measure this effect better. Such a measure could include available data on number of PCs per 100 people, number of internet users, secure internet server figures etc. However, these data items are available for only recent years. A regression relating these variables with competitiveness would raise a causality question. Does a country have a modern infrastructure now because it is competitive or is it competitive because it has a modern infrastructure? Such questions have already been eliminated by the current study with the assumption that current competitiveness is determined by past values of variables. An analysis that connects current competitiveness and current infrastructure (or any other variable) should first be subject to causality tests. The moral of this discussion is that it is not possible to have a better idea 
on whether technical / technological development as indicated by a modern infrastructure is currently not possible to measure due to data limitations. As more data becomes available on the technological development level of a large group of countries, empirical research on the issue may flourish.

The conclusion is quite unclear in the case of education. The lack of a strong relationship between education and competitiveness is against theoretical literature but apparently is not an exception for a body of literature. Taking growth literature as the one closest to the current study's vision, it can be confirmed that the current study's education relation findings are not an exception but simply another drop in an ocean of debate.

Despite established theoretical relation between human capital and economic growth, Barro and Sala-i-Martin (1995: 537) find it difficult to empirically connect the two. One other study admits that "... the channel from schooling to growth is too weak" and this situation "remains true even when we take into consideration the effect of schooling on technology adoption" (Bils and Klenov, 2000: 1177). Temple (2001) also concludes that "the aggregate evidence on education and growth, for large samples of countries, continues to be clouded with uncertainty". A recent study, on the other hand, mentions that even if education has the effect of accelerating growth, the lag may be many decades rather than simply 10 years as is the case adopted above (Szirmai, 2008: 21-22).

As a result, what can be firmly concluded is that FDI inflows have a positive impact on competitiveness. Modern infrastructure may contribute to competitiveness, but existing measures are lacking in detail and the available data on a relatively lower technology like existing telephone mainlines is simply inadequate to reflect the exact dynamics. Impact of education is also questionable but this can be a reflection of an existing uncertainty in the literature. Apparently, better measures of education or longer datasets are needed for more detailed research. Dummy coefficients from fixed effects estimation show that Turkey's competitive standing is less than average and confirm the ranking lists of CIP.

\section{CONCLUSIONS}

It's well known from the related literature that manufacturing industry is one of the major components of countries' competitiveness. It is the main source of innovations, a field for application of technological development to production, creates positive externalities for the rest of the economy and enables attainment of dynamic comparative advantage in international trade.

From this viewpoint in this study, the competitive industrial performance (CIP) index, taken to be an indicator of relative competitive ability, has been calculated for a sample of 33 countries for years 1985, 1990, 1998 and 2002. Panel data methods then have been employed to reveal sources of competitive ability. The insights obtained from the conducted analysis can be summarized 
as follows.

Indicator results imply a spatial shift of production of medium and high technology goods from developed countries to some of the developing countries. This is confirmed by CIP results where a small number of relatively less developed countries are catching up with developed countries in terms competitive ability. Turkey does not appear to be part of this process and displays poor competitive standing compared to other countries in the sample.

Econometric results confirm that Turkey is lagging behind other countries in terms of competitive ability. The negative coefficient on Turkey's dummy in fixed effects model signifies the situation. It is also observed that FDI is a major determinant of competitive ability; attempts to attract FDI would contribute to future well being of a country.

Moreover education proves to be an elusive variable in determining competitive ability. It is possible that education is not a good instrument to represent skills. Such elusive behavior of education, however, is not an uncommon occurrence and has been encountered many times in the empirical part of growth literature. One other interesting note is that econometric results imply that too much schooling may be unnecessary for development of competitive abilities. It is possible that on-the-job training or development of skills through practice is a better determinant of competitiveness than formal education.

Telephone mainlines per 100 people, as a variable, either contributes negatively to competitiveness of a country or has no effect at all. The statistical significance of negative effect is also in doubt. Two conclusions are possible: either modern infrastructure is not related to competitiveness or a better modern infrastructure measurement is necessary. A better measure is currently not possible due to unavailability of datasets with long time dimension.

Lastly, as a policy recommendation, Turkey should focus on attracting more FDI and focus on technical training of the workforce rather than concentrate on providing higher and higher levels of education.

\section{REFERENCES}

Baltagi, B. H., Econometric Analysis of Panel Data, John Wiley \& Sons Ltd. Sussex, England, (1995).

Barro, R. J. and Sala-i-Martin, X., Economic Growth, McGraw Hill: New York USA, (1995).

Barro, R.J. and Lee, J-W., "International Data on Educational Attainment: Updates and Implications", CID Working Paper No.42, Harvard University, (2000). 
Bils, M. and Klenov, P.J., "Does Schooling Cause Growth?", American Economic Review, 90(5), (2000).

Erlat, H., Panel Data: A Selective Survey, Unpublished Lecture Notes, (2008).

European Commission Staff, Eropean Competitiveness Report 2004, European Commission Staff Staff Working Document SEC(2004), 1397, (2004).

Greene, W. H., Econometric Analysis, Prentice Hall: New Jersey, USA, (2003).

Hausman, J. A., "Specification Tests in Econometrics", Econometrica, 46, (1978), Pp: 1251-1271.

Hsiao, C., Analysis of Panel Data, Cambridge University Press: Cambridge, UK, (2003).

Johnston, J. and DiNardo, J., Econometric Methods, McGraw-Hill Book Co., (1997).

Kennedy, P., A Guide to Econometrics, Blackwell Publishing: Oxford: UK, (2003).

Swamy, P. A. V. B. and Arora, S.S., "The Exact Finite Sample Properties of the Estimators of Coefficients in the Error Components Regression Models", Econometrics, 40, (1972), Pp: 261-275.

Szirmai, A., "Explaining Success and Failure in Development", United Nations University Working Paper Series, No. 2008-13, (2008).

Temple, J. R. W., "Generalizations That Aren't? Evidence on Education and Growth", European Economic Review 45(4-6), (2001).

UI Haque, I., Trade, Technology and International Competitiveness, World Bank, (1995).

UNIDO, "Industrial Development Report 2002/2003: Competing through Innovation and Learning", http://www.unido.org, (2002).

UNIDO, "Industrial Development Report 2005: Capacity Building for Catching Up; Historical, Empirical and Policy Dimesions", UNIDO Publication No. 454, http://www.unido.org, (2005). 